\title{
Economicidade do reflorestamento
}

1. Introducito. 2. Caracteristicas gerais do reflorestamento. 3. Premisess des efleutos. 4. Metodolozia. B. conolutsta.
Este trabatho visa a encarar de um modo simples a economicidade do reflorestamento. Para isso procura determinar sua taxa anual de rentabilidade em têrmos reais. Esse dado é comparado com o resultante dos demais tipos de incentivo fiscal a fim de se verificar qual o melhor dêles. Depois, procura saber, dentro do reflorestamento, qual a melhor hipótese: arrendar ou ser proprietário da terra onde se val plantar as árvores, determinando-se o ponto de equilibrio, entre as duas alternativas, em gráfico. Finalmente, conclui, baseado nesse gráfico, que é determinado por uma equação extraída das premissas do reflorestamento - que se pode pensar no reflorestamento como atividade empresarial, independente de incentivo fiscal. Para isso, a emprêsa tem de comparar o rendimento de seu negócio preclpuo com o do reflorestamento. Ora, êsse último rendimento é função do preço que se paga pela terra. 0 preço máximo, que pode ser pago em cada caso, pode ser lido diretamente no gráfico.

A seguir, são apresentadas as caracteristicas gerais do reflorestamento e as premissas que serviram de base para os cálculos. Depois, são analisados os vários aspectos económicos referidos.

2. CARACTERISTICAS GERAIS DO REFLORESTAMENTO

A atual politica de desenvolvimento nacional encara as questões referentes ao reflorestamento como prioritárias, tendo em vista os aspectos econômicos e sociais envolvidos.

Através da sistemática dos incentivos fiscais, permitiu o Govêrno federal, em fins de 1966, pela Lei n.0 5.106, que pudessem ser abatidos da rerida bruta (pessoa física) ou do impósto a pagar (pessoa jurídica) até $50 \%$ dos seus valóres, desde que êstes fóssem "efetivamente aplicados em reflorestamento no ano-base". Posteriormente, pelo Decreto-tei n.0 1.106, de 16-7-70, a partir de 1971 até 1974, inclusive, tal percentagem foi diminuida para $35 \%$, visto que, a semelhança de outros incentivos (SUDAM, SUDENE e SUDEPE), $30 \%$ daqueles $50 \%$ passaram a ser destinados a investimentos governamentais pertinentes ao Plano de Integração Nacional (PIN). Isso se refere somente às pessoas jurídicas; as pessoas físicas permanecem na lei anterior.

Mais recentemente, pelo Decreto-lei n. 1.134 , a destinação para apłicação, à semelhança de outros incentivos, passou a ser feita por ocasiăo da declaração (a percentagem permaneceu no mesmo nível), mudando então a época de execução

* Diretor-gerente da Emissor S.A. de Credito Imobiliário a Diretor da Emissor S.A. Crédito, Financiamento e Investimentos, e Emissor S.A. Corretora de Titulos $e$ Valóres Mobiliários. 
de projeto, de anterior para posterior à declaração do impôsto de renda.

o reflorestamento vem ocorrendo não só em terras pouco aptas a explorações de natureza agrícola e/ou pecuária, como, também, em terras mais férteis.

Por outro lado, o programa florestal do Govêrno de São Paulo estabelece áreas prioritárias para reflorestamento. Da conjugação dêsses dados surgem problemas quanto a niveis de preços de terras em que o reflorestamento seja atrativamente rentável. Sendo assim, utilizando valôres quantificáveis, tentaremos analisar a matéria pormenorizadamente, no sentido de oferecer maiores subsídios aos investidores ou interessados nesse mercado.

\section{PREMISSAS DOS CÁLCULOS}

0 trabalho baseia-se sempre em um alqueire de terra nas condições médias de localização e plantio, descritas logo a seguir. Sabemos que um alqueire que tem $24.200 \mathrm{~m}^{2}$ comporta aproximadamente $6 \mathrm{mil}$ árvores $\left(2 \times 2=4 \mathrm{~m}^{2}\right.$ por árvore). Entretanto, estudos recentes da matéria indicam que o espaçamento de $1,70 \mathrm{~m} \times 2,50 \mathrm{~m}$, isto é, $4,25 \mathrm{~m}^{2}$ é o mais indicado para o corte que visa a produção de celulose. Neste caso, o número de árvores cai para 5.700 unidades por alqueire. 0 custo médio do plantio e da manutenção estimado em valor presente, é de $\mathrm{Cr} \$ 0,80$ por árvore. 0 valor da terra é muito variável. Dependerá da sua localização (se próxima ou não do centro consumidor), das condições topográficas, comunicações, etc. Assim sendo, determinaremos, através dos demais elementos, o preco da terra, que poderá ser adquirida para se conseguir equilíbrio com outros investimentos. Em têrmos de produção média, são estimados os seguintes dados, tomados de forma conservadora, em $\mathrm{m}^{8}$ :

$600 \mathrm{~m}^{\mathrm{s}}$ no $13 .^{\circ}$ semestre (entre $60^{\circ} \mathrm{e}$ $7 .^{\circ}$ ano);

$350 \mathrm{~m}^{\circ}$ no $25 .^{\circ}$ semestre (entre $12 .^{\circ} \mathrm{e}$ 13. ${ }^{\circ}$ ano);

$270 \mathrm{~m}^{3}$ no $37 .^{\circ}$ semestre (entre $18 .^{\circ} \mathrm{e}$ 19. ${ }^{\circ}$ ano).

0 valor médio de venda estimado para a madeira em pé, isto é, antes do corte - livre, portanto, o dono das árvores, de despesas de corte e transporte - é de Cr\$ 8,00 por $\mathrm{m}^{3}$. Esse valor também é muito variável; foi tomado para madeira colhida em terras de topografia mais ou menos plana ou ligeiramente ondulada, e situadas num raio de cêrca de 100 $\mathrm{km}$ do centro de consumo (fábricas de papel, por exemplo). Cada quilómetro custa aproximadamente Cr $\$ 1,00$ de frete; daí surge a dependência carga $\times$ destino.
Sabemos, também, que, se houver arrendamento, a taxa do arrendatário será de $30 \%$ sôbre a receita bruta, na respectiva época.

Neste estudo, utilizamos valôres reais, isto é, não consideramos a valorização da terra, 0 aumento de custos ou do próprio valor da madeira com a inflação. Também não estamos considerando o eventual acréscimo de rentabilidade provocado pela venda das fôlhas, nos períodos intermediários, para produção de óleo de eucalipto. Essas premissas, acima estabelecidas, evidentemente irão variar diferentemente para cada caso, e de ano para ano para - mesmo caso. Basta, entretanto, simples substituição nas equações a seguir, para que se encontrem os novos parâmetros.

\section{METODOLOGIA}

4.1 Rentabilidade do arrendamento Iniciamos pelo arrendamento, que não considera 0 valor da terra. Assim, teremos mais facilidade, por têrmos, de início, uma incógnita a menos. Se o investidor trabalha desta forma, as condições serão as seguintes:

a) Desembôlso na época zero: $5.700 \times 0,80=4.560,00$

b) Retôrno de $70 \%$ da produção acima prevista, visto que $30 \%$ cabe ao arrendador.

$70 \%$ da

Produção Produção produção

Epoca $\mathrm{m}^{3}$ Cr $\$$ Cr $\$$

13..$^{\circ}$ sem. $\quad 600 \quad 4.800,00 \quad 3.360,00$ $25 .^{\circ}$ sem. $\quad 350 \quad 2.800,00 \quad 1.960,00$ $37 . .^{\circ}$ sem. $270 \quad 2.160,00 \quad 1.512,00$

Em têrmos de equação, a fim de determinarmos uma taxa anual de rendimento do capital investido, temos:

$4.560=3.360 v^{13}+1.960 v^{25}+1.512 v^{3 r}$

onde $v^{2}$ é o fator de valor atual de um capital da época $\mathbf{n}$ calculado ou avaliado para a época zero, dado pela fórmula $(1+i)^{-2}$, da qual extraímos i, a taxa procurada (já base-ano, agora). Então, determinamos para $\mathrm{i}$ (real) o valor de $3,94 \%$ a.a.

\subsection{Valor da terra em função da} rentabilidade

Nosso objetivo será o de determinar o valor da terra em função de diversas taxas de rendimento. Êsse valor será 0 preço de um alqueire, onde se efetuará o plantio. Sabemos que plantando em terra própria, o investidor "desembolsará" o valor da terra a ser determinado mais o custo do plantio e isso tudo em valôres atuais (época zero).

Sabemos, também, que após o terceiro corte, ou seja, 37.0 semestre, o investidor terá, ainda, a terra, que poderá vender ou usar para novas plantações, evidentemente após o devido trato. Neste estudo, consideramos apenas a sua venda. Se o preço de venda fôr o mesmo da aquisição, o retôrno no final, isto é, quando do último corte, será de Cr $\$ 2.160,00$ pela produção da madeira, mais o valor de venda da terra pelo preço igual ao da aquisição. É bom observar que, após - último corte, a terra não apresentará as mesmas condições da época da aquisição. Entretanto, consideramos a venda pelo mesmo preço da compra, devido, entre outros fatôres, à valorização em têrmos de desenvolvimento da região, ao aproveitamento dos tocos e raízes como carvão, etc.

Pois bem; se colocarmos, também, em têrmos de equação de equilíbrio para podermos apurar o valor da terra, teremos:

$4.560+X=4.800 v^{18}+2.800,00 v^{25}+$ $+(2.160+X) v^{37}$

onde $\mathbf{v}^{\mathbf{n}}$ será calculado utilizando-se a taxa de $3,94 \%$ a.a. encontrada na rentabilidade do arrendamento $e X$ o preço da terra a ser determinado.

Encontramos para $X$ o valor de $\mathrm{Cr} \$ 3.828,00$. Esse valor responde à indagação que tantas vêzes foi formulada aos estudiosos da matéria: "Qual a melhor alternativa: plantar em terra própria ou arrendá-la de terceiros?"

A resposta é clara: se o investidor plantar em terra própria e pagar $3.828,00$ o alqueire, a rentabilidade obtida será exatamente igual à rentabilidade a ser obtida em terra arrendada. Evidentemente, se o preço for superior a $C r \$ 3.828,00$ por alqueire, - arrendamento oferecerá melhores vantagens. Em conseqüência, se 0 preço pago fôr menor que o indicado para o equilíbrio, adquirir a terra é a melhor alternativa.

Salientamos que Cr\$3.828,00 por alqueire é o valor que reflete o equilíbrio entre compra e

arrendamento, e não o valor económicamente interessante para o empresário. Isso é função do jotencial de retôrno de cada um, como veremos abaixo. Portanto, até Cr\$ 3.828,00 por alqueire convém comprar a terra, supondo-se, é claro, que $3,94 \%$ a.a. real seja retôrno melhor que os outros incentivos fiscais permitidos.

0 mesmo procedimento da utilização da taxa de $3,94 \%$ a.a para a determinação do valor da terra foi adotado para várias taxas, determinando-se o gráfico a seguir, onde temos o valor da terra no eixo horizontal e as taxas de rendimento no eixo vertical. Outras conclusōes poderão ser tiradas, como por exemplo: 
0 arrendamento independe do valor da terra, pois ela pertence a terceiros. Então, como já foi visto, a taxa de rendimento é constante: $\left(r_{2}\right)$ é de $3,94 \%$ a.a., a qual poderá ser encontrada no eixo vertical. O ponto onde há equilíbrio entre compra e arrendamento $\left(\boldsymbol{P}_{1}\right)$, no gráfico, é o encontro entre $r_{1}$ e $r_{2 .}$ Se o investidor optar pela compra, a sua taxa de rendimento anual dependerá exclusivamente do valor pago pela terra.

Sendo proprietário da terra $\left(\mathbf{P}_{2}\right)$, 0 investidor terá um rendimento anual de $7,85 \%$ (real), que fàcilmente poderá ser, também, localizado no eixo vertical. É claro que essa consideração é apenas acadêmica, pois mesmo sendo proprietário, a terra tem um valor passivel de remuneração. Suponhamos, agora, que - investidor seja uma pessoa jurídica de atividade qualquer e venha a retirar recursos de seu negócio e aplicar em reflorestamento independente dos incentivos fiscais. Temos, por exemplo, uma emprêsa que opere a uma taxa bruta mensal de $3,3 \%$ que equivale a uma rentabilidade real de aproximadamente
$20,8 \%$ a.a. Evidentemente, nessa taxa não estão consideradas quaisquer espécies de custo dessa emprêsa, isto é, custo administrativo, patrimonial e outros. Para êsse investidor obter a mesma taxa de retôrno no plantio de árvores será necessário que possua a terra e receba, ainda, Cr $\$ 2.913,00$ por alqueire, o que será impossível, portanto $\left(P_{3}\right)$. Já, se a meta fôr obter a mesma taxa que será alcançada se investir em letras de câmbio $(7,12 \%$ a.a. real ou taxa bruta de $2 \%$ a.m. aproximadamente), poderá pagar até $\mathrm{Cr} \$ 411,00\left(\mathrm{P}_{4}\right)$ pelo alqueire da terra e, assim por diante.

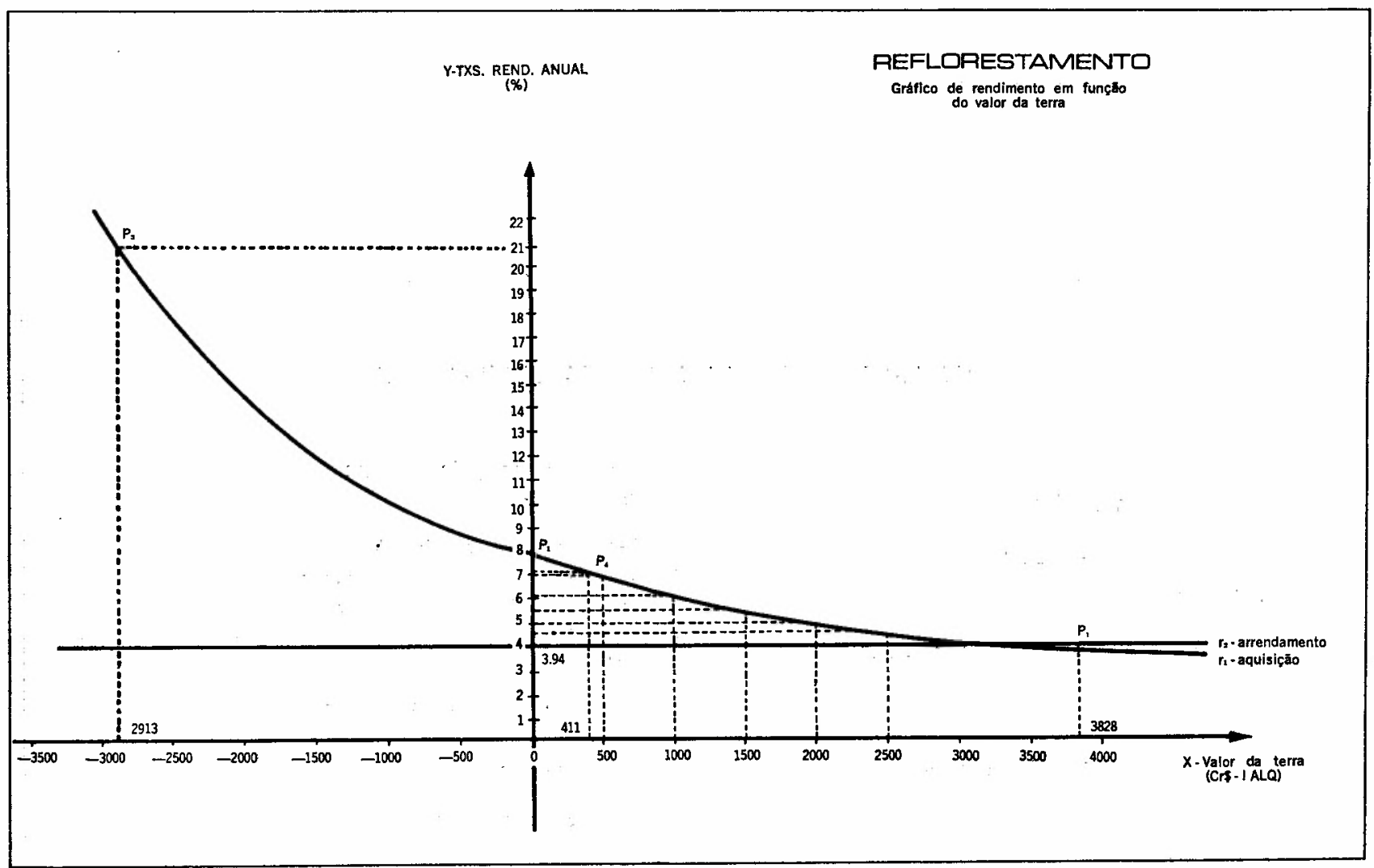

\subsection{Resumo}

\begin{tabular}{l|c|c|c}
\hline & $\begin{array}{c}\text { fatôres } \\
\text { Taxa-rendi- } \\
\text { mento bruta } \\
\text { mensal }\end{array}$ & $\begin{array}{c}\text { Taxa-rendi- } \\
\text { mento real } \\
\text { anual }\end{array}$ & $\begin{array}{c}\text { Preço } \\
\text { da terra } \\
\text { Cr\$ } \$\end{array}$ \\
\hline Arrendamento & $1,91 \%$ & $3,94 \%$ & - \\
Aquis. = Arrendam. & $1,91 \%$ & $3,94 \%$ & 3.828 \\
Aquis. = LC & $2,17 \%$ & $7,12 \%$ & 411 \\
Aquis. = Propriet. & $2,24 \%$ & $7,85 \%$ & 0 \\
Aquis. = Emprêsa & $3,32 \%$ & $20,80 \%$ & $(2.913)$ \\
& & &
\end{tabular}

A taxa de retôrno, se investir em forma de arrendamento, será de $3,94 \%$ a.a. real (ou bruta de $1,91 \%$ a.m.) e ainda independentemente do preço da terra. Se adquirir a terra, poderá pagar $\mathrm{Cr} \$ 3.828,00$ ० alqueire para obter a mesma rentabilidade de $3,94 \%$ a.a. Comparando com outras taxas de retórno, poderá pagar pelo alqueire até $\mathrm{Cr} \$ 411,00$ e conseguir a mesma taxa das letras de câmbio (2,17\% a.m. bruta), ou ainda receber
Cr\$2.913,00 também por alqueire, para obter o mesmo rendimento daquela emprêsa $(3,32 \%$ a.m. bruta). Todavia, se fôr proprietário da terra, o rendimento será de $7,85 \%$ a.a. real, ou $2,24 \%$ a.m. bruta, isto é, considerando a inflação.

\section{CONCLUSAO}

Como já foi dito, para a determinação das variáveis "valor da terra" e "taxa de rendimento", foram fixados outros elementos, que poderão ser reavaliados ou reestudados, conforme o investimento. São êles: capacidade de árvores por alqueire, custos, produção, épocas de corte, valor de venda da madeira, taxa do arrendatário, etc. Qualquer alteração dêsses dados, tomados como fixos nas equaçōes, modificará, sobremaneira, os resultados finais, gráfico, etc. 
Se levarmos em conta que os recursos das aplicaçס̃es em reflorestamento provêm de parte do impôsto de renda que uma pessoa física ou jurídica deixa de desembolsar, podemos concluir, à primeira vista, que o rendimento apurado é satisfatório, embora dependendo da análise mais acurada dos demais tipos de incentivo fiscal.

Consideremos, entretanto, a gama de hipóteses existentes em função dos valôres apresentados. Assim sendo, as conclusōes são válidas nas análises de cada caso especifico. Portanto, cada investidor, conhecendo com maior profundidade os elementos disponiveis, poderá extrair as próprias conclusōes, e com maior precisão.

Outra opção seria a do plantio de árvores frutiferas, que as normas de incentivos fiscais permitem.

Em qualquer hipótese, o importante será, no devido momento, analisarmos, também, os aspectos năo monetários, bem como outros fatôres não positivos, mas que deverão surgir na hora de decisão.

Por último, cabe ressaltar, conforme demonstram as estatísticas, que, se tudo correr conforme planejamento da esfera federal, o nosso País poderá ser o celeiro de madeira para 0 mundo, dentro dos próximos 30 anos; dal os fatôres: procura, exportação, preços, etc.

\section{PROXIMOS LANÇAMENTOS DA FUNDAÇAO GETÚlIO VARGAS}

Dispersos

J. Mattoso Câmara Júnior

Desenvolvimento Global - Utopia ou Realidade?

Vários autores

Industrialização e Concentração Econômica em São Paulo

Henrique Rattner

Origem e Evolução dos Descritores

Benedicto Silva

Saúde e Sistemas

Mário M. Chaves

Análise Contábil - Análise de Balanços Américo M. Florentino
Desenvolvimento pela Ciência

Jacques Spaly

Contas Nacionais do Brasil

$1 .^{\circ}$ volume - Conceitos e Metodologia

2.0 volume - Quadros Estatísticos

Instituto Brasileiro de Economia - Centro de Contas Nacionais

Do Estado Liberal ao Estado Social

3. a ediçāo

Paulo Bonavides

A Arte da Administração

2.a edição, 2.a tiragem

Ordway Tead

Teoria das Organizaçōes

2.a ed., 2. a tiragem

J. March \& H. Simon

Visite uma das suas livrarias

Guanabara

Avenida Graça Aranha, 26, C e H - Tel.: 222-4142

Praia de Botafogo, 188 - Tel.: 246-5107

São Paulo

Avenida Nove de Julho, 2029 - 288-3893

Brasília

Super Quadra, 104, Bloco "A" Loja 11 - Tel.: 24-3008 